\title{
Upregulation of PAX2 Promotes the Metastasis of Esophageal Cancer through Interleukin-5
}

\author{
Pengfei Liu ${ }^{a} \quad$ Yi Gao $^{a}$ Jian Huan ${ }^{b} \quad$ Xin Ge ${ }^{c, d} \quad$ Yiting Tang ${ }^{c, d} \quad$ Wenhao Shen ${ }^{c, d}$ \\ Ye Tian ${ }^{d}$ Weidong Shen ${ }^{a}$ Shitao Zou ${ }^{e}$ Jundong Zhou ${ }^{e}$ Shuyu Zhang ${ }^{c, d}$ \\ aDepartment of Gastroenterology, the Affiliated Jiangyin Hospital of Southeast University, Jiangyin, \\ 'Department of Radiotherapy, The Second Affiliated Hospital of Soochow University, Suzhou, 'School \\ of Radiation Medicine and Protection and Jiangsu Provincial Key Laboratory of Radiation Medicine \\ and Protection, Medical College of Soochow University, Suzhou, ${ }^{\mathrm{d} C o l l a b o r a t i v e ~ I n n o v a t i o n ~ C e n t e r ~}$ \\ of Radiation Medicine of Jiangsu Higher Education Institutions and School for Radiological and \\ Interdisciplinary Sciences (RAD-X), Soochow University, Suzhou, ${ }^{e}$ The Core laboratory of Suzhou Cancer \\ Center and Department of Radiotherapy of Suzhou Municipal Hospital, Suzhou, China
}

\section{Key Words}

Esophageal squamous cell carcinoma (ESCC) - Paired box gene 2 (PAX2) - Metastasis - Interleukin-5 (IL-5)

\begin{abstract}
Background/Aims: This study investigated the clinical relevance and biological function of paired box gene 2 (PAX2) in esophageal squamous cell carcinoma (ESCC). Methods/Results: Results showed that PAX2 expression was significantly increased in tumor tissues and that its expression correlated with the ESCC stage $(P=0.001)$, lymph node metastasis $(p N, P=0.019)$ and lymphatic invasion ( $P=0.005)$ in 120 ESCC tissue specimens by immunohistochemistry. Furthermore, PAX2 overexpression resulted in markedly reduced cell proliferation but increased metastasis capacity in ESCC TE-1 and Eca-109 cells. Knockdown of PAX2 expression with a short hairpin RNA confirmed a role in the promotion of metastasis in ESCC cells. mRNA microarray screening revealed that PAX2 overexpression affected multiple genes that function in multiple pathways. Interleukin-5 (IL-5), which was induced by PAX2 and has been shown to promote tumor metastasis, was further studied in greater detail. Two PAX2 binding sites were identified in the IL-5 promoter, and PAX2 was observed to stimulate IL-5 promoter activity and IL-5 expression in esophageal cancer cells. Chromatin immunoprecipitation (ChIP) confirmed the direct binding of PAX2 in the IL-5 promoter. The expression of PAX2 mRNA significantly correlated with that of IL-5 in normal esophageal and ESCC tissues. Conclusion: These findings demonstrate that PAX2 is overexpressed in esophageal carcinoma and IL-5 is identified as PAX2's effector for metastasis.
\end{abstract}

P. Liu, Y. Gao and J. Huan contributed equally to this work.

Pengfei Liu,

and Shuyu Zhang

KARGER 125
No.163 Shoushan Rd, the Affiliated Jiangyin Hospital of Southeast University, Jiangyin 214400 (China) and No. 199 Ren'ai Rd, Medical College of Soochow University, Suzhou 215123 (China), E-Mail pengfeimd@163.com, E-Mail zhang.shuyu@hotmail.com 
Liu et al.: Upregulation of PAX2 Promotes Metastasis in ESCC

\section{Introduction}

Esophageal cancer ranks as the ninth most common malignancy and the sixth most common cause of cancer-related death, with elevated incidence and mortality rates in developing countries $[1,2]$. Approximately one-half of newly diagnosed esophageal cancer cases occur in China each year, and esophageal squamous cell carcinoma (ESCC) constitutes more than $90 \%$ of esophageal cancer diagnoses. Despite the currently available methods of aggressive treatment for ESCC, the prognosis of this cancer remains poor because of late diagnosis and the rapid metastasis of cancer cells $[3,4]$. The pathology of ESCC remains complex and largely unknown. Transcription factors are central to cancer initiation and progression, serving as "switches" that turn specific sets of genes on or off $[5,6]$.

The paired box (PAX) transcription factor family is characterized by a highly conserved paired-box DNA-binding domain. At present, nine paired box genes (PAX1 to PAX9) are known to occur in human beings [7, 8]. The temporal and spatial expressions of PAX genes are tightly regulated during embryogenesis. PAX2 is primarily expressed in embryo and downregulated when the development is completed [8]. PAX2 is widely expressed during the development of both ductal and mesenchymal components of the urogenital system. Moreover, PAX2 plays a critical role in the formation of the isthmic organizer that controls midbrain and cerebellum development by activating En2, Brn1, Sef, Tapp1 and Ncrms [9]. PAX2 expression can only be detected in the medullary regions of the kidney, the transitional urothelium of the ureter and bladder wall and the epithelial lining of the fallopian tube in adults $[10,11]$. Specific mutations in PAX2 genes lead to a range of developmental abnormalities in both human beings and mouse models $[12,13]$.

In recent years, PAX2 has been found to be re-expressed in multiple cancers, including renal [14-16], ovarian [17, 18], endometrial [19] and breast cancers [20]. Furthermore, the expression of PAX2 plays versatile roles in cancer progression. PAX2 suppresses Caspase-2induced apoptosis in the renal collecting duct, thus stimulating proliferation and self-renewal [11]. A recent study has shown that PAX2 induces expression of Cyclin D1 by activating AP-1 and promotes the proliferation of colon cancer cells [21]. PAX2 is hyper-expressed in human metastatic prostate cancer, and knockdown of PAX2 represses cell growth and invasion [22]. Therefore, PAX2 has emerged as a hallmark of malignant cells, suggesting that it might be a potential target for cancer therapy [23, 24]. However, the role of PAX2 in cancer development may vary depending on the underlying tissue-specific conditions; furthermore, the biological significance of PAX2 may vary between cancer cells.

The clinical relevance of PAX2 and its biological function in ESCC have remained unclear. In this study, we investigated the expression of PAX2 and its functional consequences in ESCC. We demonstrate that PAX2 expression is significantly overexpressed in ESCC tissues compared to expression levels in normal tissues. In addition, PAX2 promotes metastasis through interleukin-5 (IL-5) in ESCC TE-1 and Eca-109 cells.

\section{Materials and Methods}

\section{Tissue samples}

For immunohistochemistry, 120 ESCC samples and 52 matched, adjacent normal esophagus tissues were collected from 102 patients, as previously reported $[25,26]$. Fifteen normal esophageal tissues were obtained from surgical resections of trauma patients. These tissues were obtained postoperatively between 2010-2012 from the Gastrointestinal Center, Jiangyin People's Hospital, Medical School of University of Southeast of China (Jiangyin, China). For real-time PCR analysis, another 60 human ESCC tissues were used, as previously reported [25].

All patients gave signed, informed consent for their tissues to be used for scientific research. Ethical approval for the study was obtained from the Jiangyin People's Hospital. All diagnoses were based on pathological and/or cytological evidence; the histological features of the specimens were evaluated by two senior pathologists according to the classification criteria from the WHO [27]. 
Liu et al.: Upregulation of PAX2 Promotes Metastasis in ESCC

\section{Immunohistochemistry (IHC)}

Three-micrometer-thick tissue paraffin sections were deparaffinized and heat-treated with citrate buffer, $\mathrm{pH}$ 6.0, for $7 \mathrm{~min}$ as an epitope retrieval protocol. Endogenous peroxidase was blocked with $3 \%$ hydrogen peroxide for $15 \mathrm{~min}$ at room temperature, and non-specific-binding sites were blocked with $4 \%$ skimmed milk powder for $30 \mathrm{~min}$. Sections were then incubated with the PAX2 antibody (Santa Cruz Biotechnology, Santa Cruz, CA) for $1 \mathrm{~h}$ (dilution 1:200) and mixed with 2\% skimmed milk powder to again reduce unspecific staining. Biotinylated secondary antibody was then added for 30 min. Avidinbiotin-peroxidase complex (Dako LSAB2 system, DAKO Co., Carpinteria, CA) was added, and the color was developed using 3-3'-diaminobenzidine. Counterstaining was performed with hematoxylin. All steps were performed at room temperature.

IHC scoring was based on both cytoplasmic and nucleic staining. The stained sections were scored using the following criteria as reported previously $[25,26]$ : negative $(-),<10 \%$ of the whole tissue mass stained; weakly positive ( +1$), 10-25 \%$ of the whole tissue mass stained; moderately positive $(+2), 25-75 \%$ of the whole tissue mass stained; and strongly positive $(+3),>75 \%$ of the tissue showed positive.

Reverse transcriptase-PCR (RT-PCR) and real-time PCR analysis.

Total RNA from esophageal tissues was extracted with TRIzol (Invitrogen, Carlsbad, CA) and reversely transcribed to cDNA using an oligo $(\mathrm{dT})_{12}$ primer and Superscript II (Invitrogen). The mRNA levels of target genes and the internal standard glyceraldehyde 3-phosphate dehydrogenase (GAPDH) were measured by RTPCR or real-time PCR in triplicate on a Prism 7500 real-time PCR machine (Applied Biosystems, Foster City, CA). The specific primers for the genes are listed in Table 1.

PAX2 overexpression and RNAi

The human PAX2 (GenBank accession no. ENST00000428433) coding region was amplified by PCR using a primer pair specific to $P A X 2$. The amplified fragment was inserted into the pcDNA3.1 vector. The plasmid was then sequenced for confirmation. The siRNA targeting PAX2 and siRNA control (siRNA-NC) used in this study were obtained from Santa Cruz Biotechnology (Santa Cruz, CA).

\section{Cell culture and transfection}

The human esophageal cancer cell lines, TE-1 and Eca-109, was maintained in DMEM supplemented with $10 \%$ FBS and antibiotics (Gibco, Grand Island, NY). Cells were grown in a $37^{\circ} \mathrm{C}$ incubator with $5 \% \mathrm{CO}_{2}$. For transfection, cells were transfected by Lipofectamine 2000 (Invitrogen, Carlsbad, CA) with plasmids or siRNAs.

\section{Cell viability assay}

Cell viability was evaluated using the 3-(4,5-dimethylthiazol-2-yl)-2,5-diphenyl-2H-tetrazolium bromide (MTT) assay. Cells were plated in 96-well plates. The next day, the cells were transfected with plasmids or siRNAs according to the experimental design. The cells were then incubated with $20 \mu \mathrm{l}$ MTT ( 5 $\mathrm{mg} / \mathrm{ml}$ ) for $4 \mathrm{~h}$. After the medium was removed, $100 \mu \mathrm{l}$ DMSO was added and the optical density (OD) at 490 $\mathrm{nm}$ was measured using a Microplate Reader (Bio-Rad, Hercules, CA). The viability index was calculated as experimental OD value/control OD value. Three independent experiments were performed in quadruplicate.

\section{Focus formation}

Cells transfected with the indicated vectors were plated at low density (1,000 cells per 6-cm plate), incubated for 10 days and fixed and stained with crystal violet. Foci and colonies containing more than 50 cells were counted using a microscope.

Table 1. Primer sequences for RT- PCR analysis

\begin{tabular}{lll}
\hline Gene & Forward primer & Reverse primer \\
\hline CNTNAP5 & 5'-GGGAACCACTCACAAATGCT -3' & 5'- TTCTCCTTCATCTGGCTCGT -3' \\
IL5 & 5'-AACTGTGCAAGGGGGTACTG -3' & 5'- ATCTTTGGCTGCAACAAACC -3' \\
Cadherin8 & 5'-ATCGATGGAGATGGAACAGC -3' & 5'- GAACTGCCTCTCCAGGTCAG -3' \\
THRB & 5'-GAACAGTCGTCGCCACATCTC -3' & 5'- TCTTGCTGTCATCCAGCACCAAATC -3' \\
TRAF5 & 5'-CTGTGCTGTAACGGATAAACGG -3' & 5'- TAGCTGCTGGATTTTACTTTCTTTC -3' \\
GAPDH & 5'-GAAGGTGAAGGTCGGAGTC-3' & 5'-GAAGATGGTGATGGGATTTC-3' \\
\hline
\end{tabular}


Liu et al.: Upregulation of PAX2 Promotes Metastasis in ESCC

In vitro migration assay

Migration was assayed using a modified Boyden chamber (Corning-Costar, Cambridge, MA) that contained a polycarbonate transwell membrane filter $(6.5 \mathrm{~mm}$ diameter, $8 \mu \mathrm{m}$ pore size). The upper chamber was plated with $1 \times 10^{5}$ TE- 1 or Eca-109 cells in serum-free DMEM. The lower chamber contained $600 \mu \mathrm{l}$ medium from vector- or siRNA-transfected cells. After $5 \mathrm{~h}$ incubation at $37^{\circ} \mathrm{C}$ in $5 \% \mathrm{CO}_{2}$, the filter was removed. Non-migrated cells on the upper surface of the filter were wiped off. Migrated cells that remained on the bottom surface were fixed with methanol, stained with Giemsa and counted under a microscope. To confirm the involvement of MMPs, $10 \mathrm{nM}$ batimasta (obtained from Selleck Chemicals, Houston, TX) was used.

\section{Western blot}

Cells were lysed in Lysis buffer (Promega, Madison, WI) and centrifuged at $4{ }^{\circ} \mathrm{C}$ for $10 \mathrm{~min}$. The supernatant was collected and subjected for Western-blot. Cytosolic and nuclear protein was extracted using the cytosolic and nuclear protein extract kit (Beyotime, Nantong, China). Fifty micrograms of protein from each lysate were fractionated by 10\% SDS-PAGE and transferred to polyvinylidene difluoride membranes (Millipore, Bedford, MA). After blocking with 5\% nonfat milk in PBS-Tween-20 for $1 \mathrm{~h}$ at room temperature, the membranes were blotted with the appropriate PAX2 (Santa Cruz Biotechnology, Santa Cruz, CA), P21, MMP-2, MMP-9 or GAPDH primary antibody (All from Santa Cruz Biotechnology, Santa Cruz, CA) at a 1:1000 dilution. Membranes were then incubated with appropriate secondary antibodies linked to horseradish peroxidase at a 1:2000 dilution for $1 \mathrm{~h}$ at room temperature. After TBST washes, the blot was incubated in the ECL detection kit (Amersham Bioscience, Freiburg, Germany).

\section{Microarray analysis}

Microarray-based mRNA expression profiling was performed using the Roche-NimbleGen (135K array) Array (Roche, WI). The microarrays contained approximately 45,033 assay probes corresponding to all of the annotated human mRNA sequences (NCBI HG18, Build 36). Total RNA labeling and hybridization were performed using standard conditions according to manufacturer instructions. Genes with a fold change of 5 or greater were subsequently subjected to pathway analysis using Ingenuity Pathway Analysis (Redwood City, CA).

\section{Luciferase assays}

Two luciferase reporters containing fragment of the PAX2 promoters $(-1322$ to +1 and -960 to +16 , relative to the transcription start site, respectively) was constructed by Shanghai Biobuy Co. Ltd. (Shanghai, China). For the luciferase assay, the reporter vector with the PAX2 promoter was co-transfected with pRL-TK (Promega, Madison, WI) to correct the transfection efficiency. Luciferase activity was measured with the Dual-Luciferase Reporter Assay System (Promega). Promoter activities were expressed as the ratio of Firefly luciferase to Renilla luciferase activities.

\section{Quantitative chromatin immunoprecipitation (ChIP)}

Eca-109 cells were used for ChIP assays. We used the EZ ChIP Kit (Upstate, Biotechnology, Lake Placid, NY) and followed the manufacturer's instructions as reported previously [28]. Briefly, $5 \times 10^{6}$ cells were cross-linked with $1 \%$ formaldehyde and sonicated to approximately $500 \mathrm{bp}$ fragments. ChIP was conducted with antibodies against PAX2 and IgG. Input control DNA or immunoprecipitated DNA was amplified in a $20 \mu \mathrm{l}$ reaction volume consisting of $4 \mu \mathrm{l}$ eluted DNA template and primers specific for $I L-5$ promoter: (forward) 5'-TCTCCCTGCTATACTGACATCG-3' and (reverse) 5'-TTCCCAGTAGTTGTCCCATACA-3'. Both the immunoprecipitated fragments and the inputs were amplified by RT-PCR or real-time PCR (the PCR product is $330 \mathrm{bp}$ ).

\section{Statistical analysis}

Data are expressed as the mean \pm standard error of the mean (SEM) of at least three independent experiments. Standard error bars were included for all data points. The data were then analyzed using Student's t test when only two groups were present or assessed by one-way analysis of variance (ANOVA) when more than two groups were compared. Correlation analysis of the mRNA expression data was performed using the Pearson test. Statistical analysis was performed using SPSS software (Release 17.0, SPSS Inc.). Data were considered significant if $P<0.05$. 
Liu et al.: Upregulation of PAX2 Promotes Metastasis in ESCC

Table 2. Patient demographics for the IHC analysis

\begin{tabular}{lcccccc}
\hline & Normal & Grade I & Grade II & Grade III & Grade III & All Tumors \\
\hline Number & 15 & 16 & 59 & 40 & 5 & 120 \\
Mean age (year) & 58.7 & 62.7 & 59.7 & 57.7 & 60.3 & 59.45 \\
Age range (year) & $32-72$ & $55-69$ & $33-76$ & $32-75$ & $49-67$ & $32-78$ \\
Sex & & & & & & \\
Male & 10 & 11 & 42 & 28 & 5 & 86 \\
Female & 5 & 5 & 17 & 12 & 0 & 34 \\
\hline
\end{tabular}

Fig. 1. Upregulation of PAX2 in ESCC samples. (A) Representative IHC staining of PAX2 expression in normal esophageal tissue specimen and ESCC tissues (magnification, $\times 100$ ). Green arrows indicate nuclear distribution of PAX2 and red arrows indicate cytoplasmic distribution of PAX2 protein in esophageal cancer cells. (B) Western blot analysis of PAX2 expression in nucleic and cytoplasmic extract of TE-1 cells after transfection with pcDNA3.1 or pcDNA3.1-PAX2. (C) Box plot representing the range of PAX2 immunohistochemical (IHC) staining score in normal esophageal tissues $(n=15)$, ESCC tissues $(\mathrm{n}=120)$ and tumor adjacent tissues $(\mathrm{n}=52), * P<0.05$.

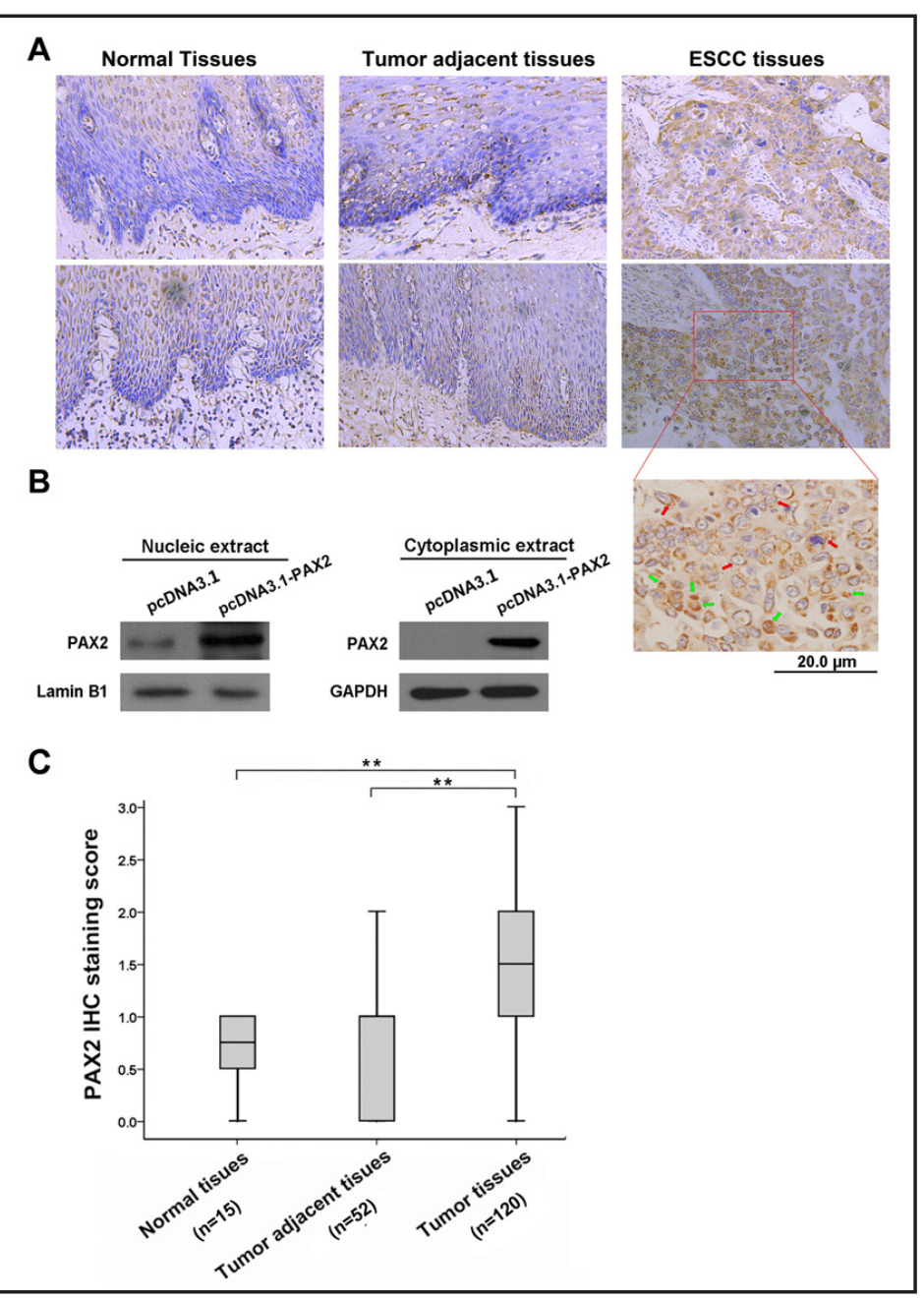

\section{Results}

Expression of PAX2 is upregulated in esophageal cancer tissues

To test the hypothesis that normal and cancerous esophageal tissues express different subsets of the PAX2 gene, we measured PAX2 expression by immunohistochemistry. Immunohistochemical staining was performed in 15 paraffin-embedded normal esophageal tissues and 120 ESCC tissues, 52 of which had corresponding adjacent tumor tissues. The histopathological features of the patients are summarized in Table 2. An overall stronger staining for PAX2 was frequently observed in the ESCC tissues, whereas very weak staining of PAX2 was observed in the normal samples (Fig. 1A). Moreover, PAX2 protein is located in both the nucleus (green arrows) and cytoplasm (red arrows) of esophageal cancer cells. To confirm the distribution of PAX2 in cultured cells, TE-1 cells were transfected with a 
Table 3. Relationship between clinicopathological and PAX2 expression in esophageal squamous cell carcinoma (ESCC) $(n=120)$. $p N$, lymph node metastasis

\begin{tabular}{|c|c|c|c|c|}
\hline \multirow{2}{*}{ Clinicopathological parameters } & \multicolumn{3}{|c|}{ PAX2 expression } & \multirow{2}{*}{$P$-Valu } \\
\hline & Case & Mean & \pm SEM & \\
\hline Age (years) & & & & 0.748 \\
\hline$<64$ & 70 & 1.593 & 0.093 & \\
\hline$\geq 64$ & 50 & 1.515 & 0.149 & \\
\hline Gender & & & & 0.145 \\
\hline Male & 86 & 1.664 & 0.109 & \\
\hline Female & 34 & 1.440 & 0.109 & \\
\hline Histological grade & & & & 0.640 \\
\hline Well & 29 & 1.638 & 0.157 & \\
\hline Moderately & 58 & 1.509 & 0.115 & \\
\hline Poorly & 33 & 1.621 & 0.151 & \\
\hline $\mathrm{pN}$ & & & & 0.019 \\
\hline$(+)$ & 73 & 1.819 & 0.127 & \\
\hline$(-)$ & 47 & 1.411 & 0.096 & \\
\hline Stage & & & & 0.001 \\
\hline 1 & 16 & 1.000 & 0.204 & \\
\hline 2 & 59 & 1.449 & 0.095 & \\
\hline 3 & 40 & 1.875 & 0.140 & \\
\hline 4 & 5 & 2.400 & 0.400 & \\
\hline Lymphatic invasion & & & & 0.005 \\
\hline$(+)$ & 63 & 1.816 & 0.116 & \\
\hline$(-)$ & 57 & 1.349 & 0.099 & \\
\hline
\end{tabular}

PAX2-overexpressing vector (pcDNA.3.1-PAX2) or a control vector (pcDNA3.1). Result form Western blot showed that PAX2 was present in the nucleic and cytoplasmic extract of PAX2overexpression cells (Fig. 1B).

The samples were further scored by a pathologist, as described in the Materials and Methods section. As shown in Fig. 1C, PAX2 expression in normal esophageal tissues was similar to that in adjacent tumor tissues; however, there were significant differences in the expression of PAX2 among tumor tissues and between tumor tissues and adjacent tumor tissues ( $P=0.002$ and $P=0.003$, respectively; Fig. $1 C)$. These results indicated an increase in the expression of PAX2 in esophageal carcinoma, suggesting a characteristic of this malignancy.

\section{Association of PAX2 expression with clinicopathological factors}

We next examined the association between the clinicopathological features and the expression of PAX2 in ESCC. As shown in Table 1, PAX2 expression correlated with an advanced tumor stage $(P=0.001)$. The expression of PAX2 was found to be significantly higher in Stage III-IV tumors than in Stage I-II tumors (1.353 \pm 0.088 vs. $1.933 \pm 0.133, P<$ $0.0001)$. The expression of PAX2 was also associated with lymph node metastasis $(\mathrm{pN})(P=$ $0.019)$ and lymphatic invasion $(P=0.005)$. Other clinicopathological parameters, including age, gender and differentiation, were not related to PAX2 expression (Table 3).

PAX2 suppressed esophageal cancer cell growth in vitro

To explore the role of PAX2 in esophageal cancer cell growth, cells were first transfected with a PAX2-overexpressing vector (pcDNA.3.1-PAX2) or a control vector (pcDNA3.1), and the resulting growth was measured by the MTT assay and colony formation. The results showed that increased PAX2 expression suppressed cell growth and proliferation, as evidenced by decreased cell viability and colony size in both TE-1 and Eca-109 cells (Fig. 2A, 2C, 2E and 2G). We further knocked down PAX2 expression using an siRNA. The downregulation of PAX2 promoted cell proliferation and colony formation (Fig. 2B, 2D, 2F and 2H). Western blot analysis further showed that PAX2 expression correlated with P21 expression (Fig. 4A$4 \mathrm{D})$, which is reported to be a negative regulator of cell cycle progression [29, 30]. Taken together, these results indicate that PAX2 suppresses esophageal tumor growth in vitro. 


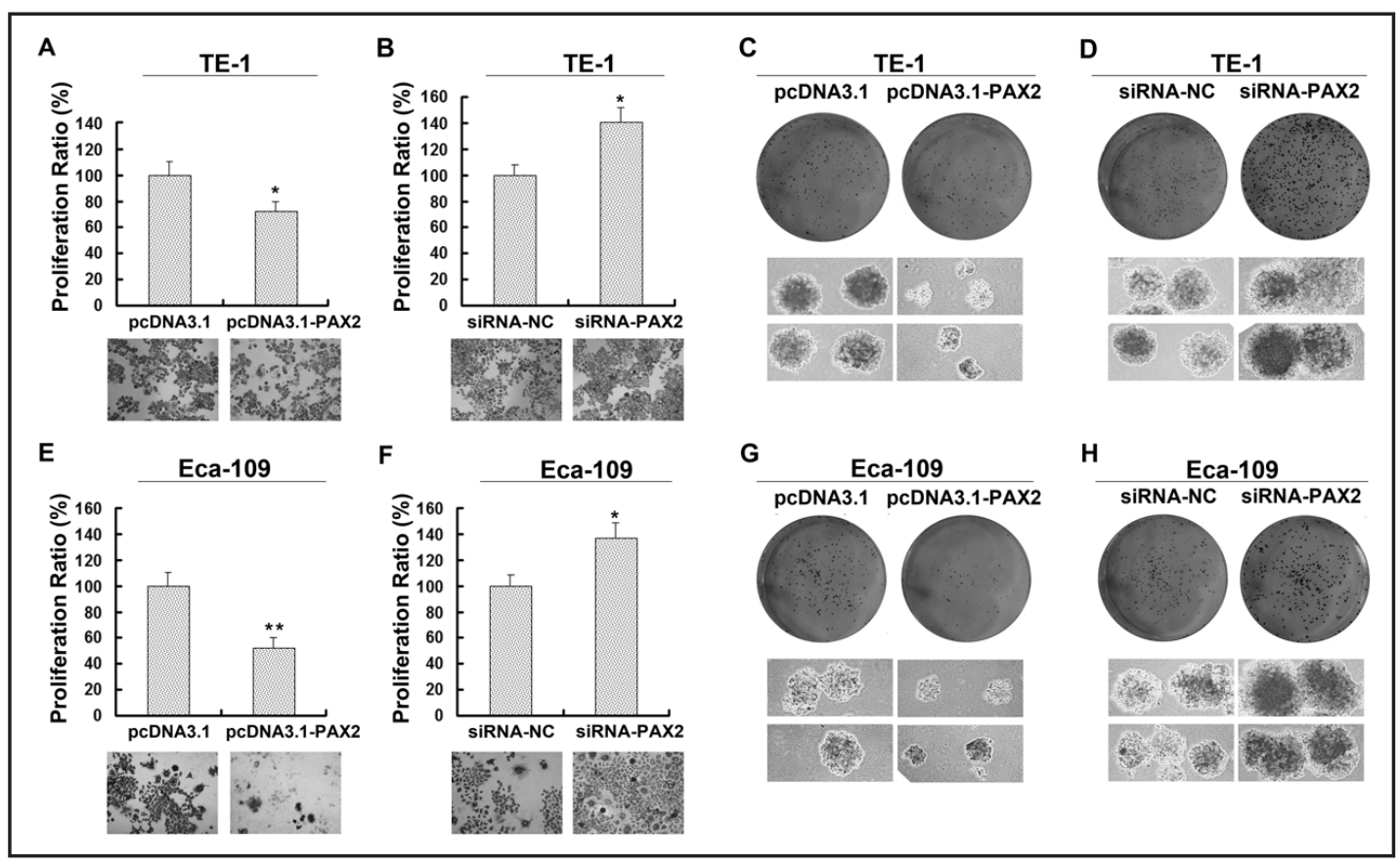

Fig. 2. The effect of PAX2 on cell proliferation and focus formation. TE-1 cell lines were seeded in a 96well plate and incubated for $48 \mathrm{~h}$. (A) Cells were transfected with pcDNA3.1 or pcDNA3.1-PAX2. (B) Cells were transfected with siRNA-control (siRNA-NC) or siRNA-PAX2. Cell proliferation was measured by MTT. Data are presented as means \pm SEM and were normalized to the control cells, ${ }^{*} P<0.05$; ${ }^{* *} P<0.01$. (C) and (D) The effect of PAX2 on TE-1 cell focus formation. TE-1 cells were transfected with pcDNA3.1, pcDNA3.1-PAX2, siRNA-control (siRNA-NC) or siRNA-PAX2. One thousand cells were seeded onto each plate. After 10 days, cells were stained with crystal violet. Colonies consisting of more than 50 cells were counted. The upper panel shows the representative focus, and the lower panel shows the representative clones. (E) and (F) Eca-109 cells were stably transfected with pcDNA3.1, pcDNA3.1-PAX2, siRNA-control (siRNA-NC) or siRNA-PAX2. Cell proliferation was measured by MTT assay. (G) and (H) The effect of PAX2 on Eca-109 cell focus formation. Eca-109 cells were stably transfected with indicated vectors. The upper panel shows the representative focus, and the lower panel shows the representative clones.

\section{PAX2 promoted migration esophageal cancer cells}

The effect of PAX2 on TE-1 cell migration was measured using migration chambers. Conditioned medium from pcDNA3.1-PAX2-transfected TE-1 cells induced a 2-fold increase in TE-1 cell migration relative to conditioned medium from pcDNA3.1-transfected cells (Fig. 3A). Conversely, conditioned medium from the siRNA targeting PAX2-transfected TE-1 cells significantly decreased the number of migrated cells compared to the number of control cells (Fig. 3B and 3C). Consistent results were obtained from Eca-109 cells (Fig. 3D to $3 \mathrm{~F}$ ). Western blot analysis showed that overexpression of PAX2 increased the expression of the metastasis effectors MMP2 and MMP9 (Fig. 4A and 4C), whereas knockdown of PAX2 decreased their expression (Fig. 4B and 4D) in both TE-1 and Eca-109 cells. To confirm the involvement of MMPs, transwell assay using batimasta, a well-established MMPs inhibitor, was conducted, Results showed that batimasta abolished PAX2-induced cell invasion (Fig. 5), indicating that MMPs is involved in promoting cell migration. Taken together, these results indicated the metastasis-promoting role of PAX2 in esophageal cancer cells.

mRNA microarray screening of PAX2-affected genes

To further analyze the underlying mechanisms responsible for PAX2-mediated metastasis, we screened gene expression between pcDNA3.1 and pcDNA3.1-PAX2- 


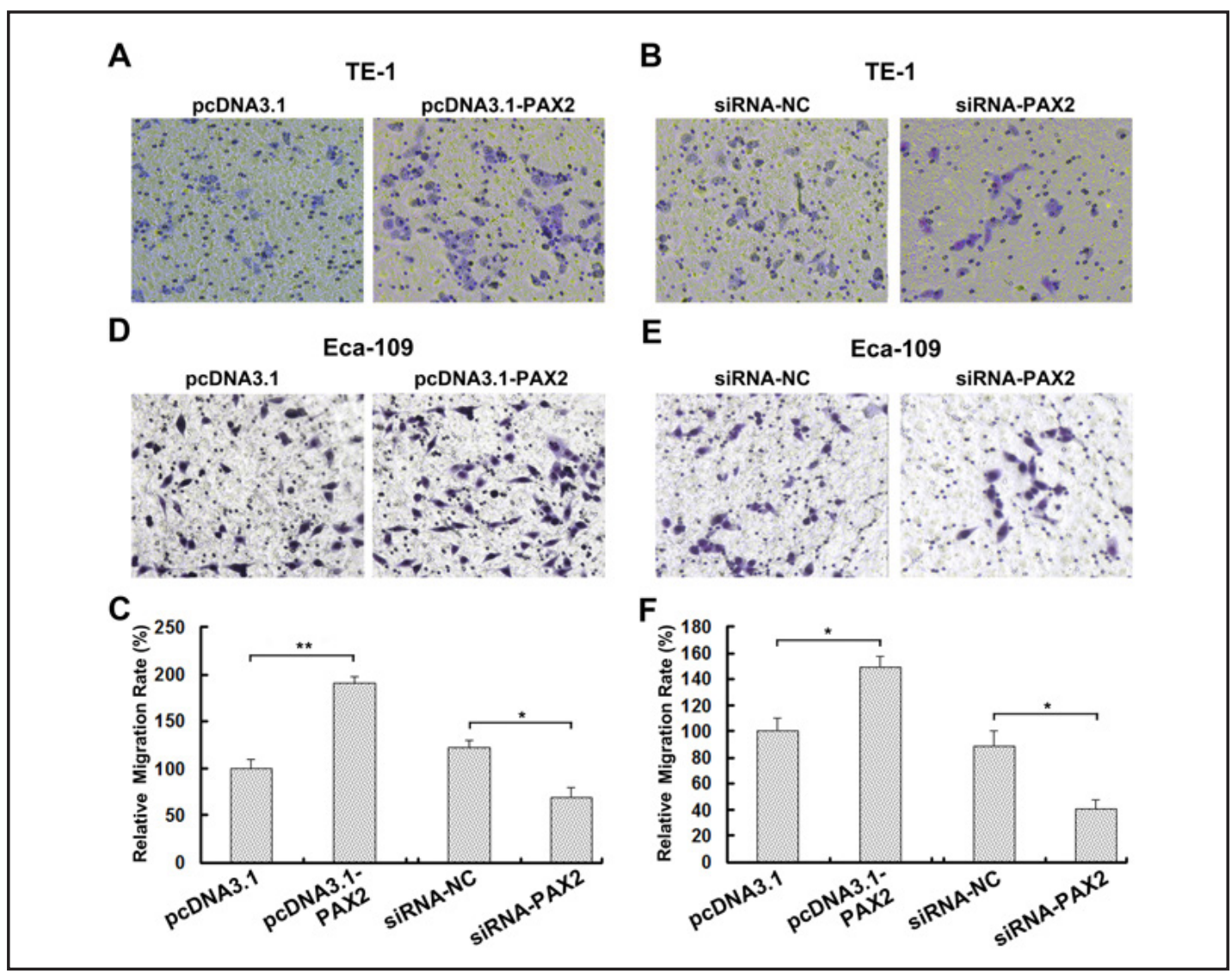

Fig. 3. The effect of PAX2 on cell migration in TE-1 and Eca-109 cells. Migration of cells was assessed using transwells (Corning) with polycarbonate inserts featuring a pore size of $8 \mu \mathrm{M}$, coated with growth factor-reduced Matrigel (BD Bioscience). Conditioned media from (A) pcDNA3.1- or pcDNA3.1-PAX2-transfected TE-1 cells or (B) siRNA-NC- or siRNA-PAX2-transfected TE-1cells were collected and assayed for their ability to induce cell migration. Migration through the membrane was determined after $24 \mathrm{~h}$ of incubation at $37^{\circ} \mathrm{C}$. Cells remaining on the topside of the transwell membrane were removed using a cotton swab, and cells that migrated to the bottom were stained with $0.5 \%$ crystal violet. (C) Calculated relative migrated TE-1 cells. The values shown are for three independent experiments. Data are presented as means \pm SEM and were normalized to the control cells, ${ }^{*} P<0.05$; ${ }^{* *} P<0.01$. Conditioned media from (D) pcDNA3.1- or pcDNA3.1-PAX2-transfected Eva-109 cells or (E) siRNA-NC- or siRNA-PAX2-transfected Eca-109 cells were collected and used for transwell assay. (F) Calculated relative migrated Eca-109 cells. The values shown are for three independent experiments.

transfected TE-1 cells (Fig. 6A). Twenty-four hours after the transfection, a total of 212 genes (80 upregulated and 132 downregulated genes) were identified with an expression differential of 5-fold or greater between the two conditions (Fig. 6B and Table 4). The raw array measures are accessible through Gene Expression Omnibus (GEO) series accession number GSE64093. We then validated the results from microarray analysis by RT-PCR. As shown in Fig. 6C, compared with irradiated cells, several genes dysregulated in microarray data, such as CNTNAP5, IL-5 and THRB, were remarkably increased in PAX2 overexpression cells, whereas the expression of TRAF5 was decreased, which was consistent with the microarray results. As expected, PAX2 appeared to have modulated the TE- 1 cells via complex mechanisms. Pathway analysis revealed that PAX2 affected multiple pathways, including Wht-protein binding, RNA polymerase II transcription factor binding and cytokine activity (Fig. 6D and 6E).

\section{KARGER}


Fig. 4. PAX2 modulated the expression of matrix metalloproteinases (MMPs). TE-1 cells were transfected with the indicated vectors (A) or siRNAs (B) for $48 \mathrm{~h}$. Cell extracts were subjected to Western blot analysis for PAX2, P21, MMP-2 and MMP-9. Eca-109 cells were transfected with the indicated vectors (C) or siRNAs (D) for $48 \mathrm{~h}$. Cell extracts were subjected to Western blot analysis.

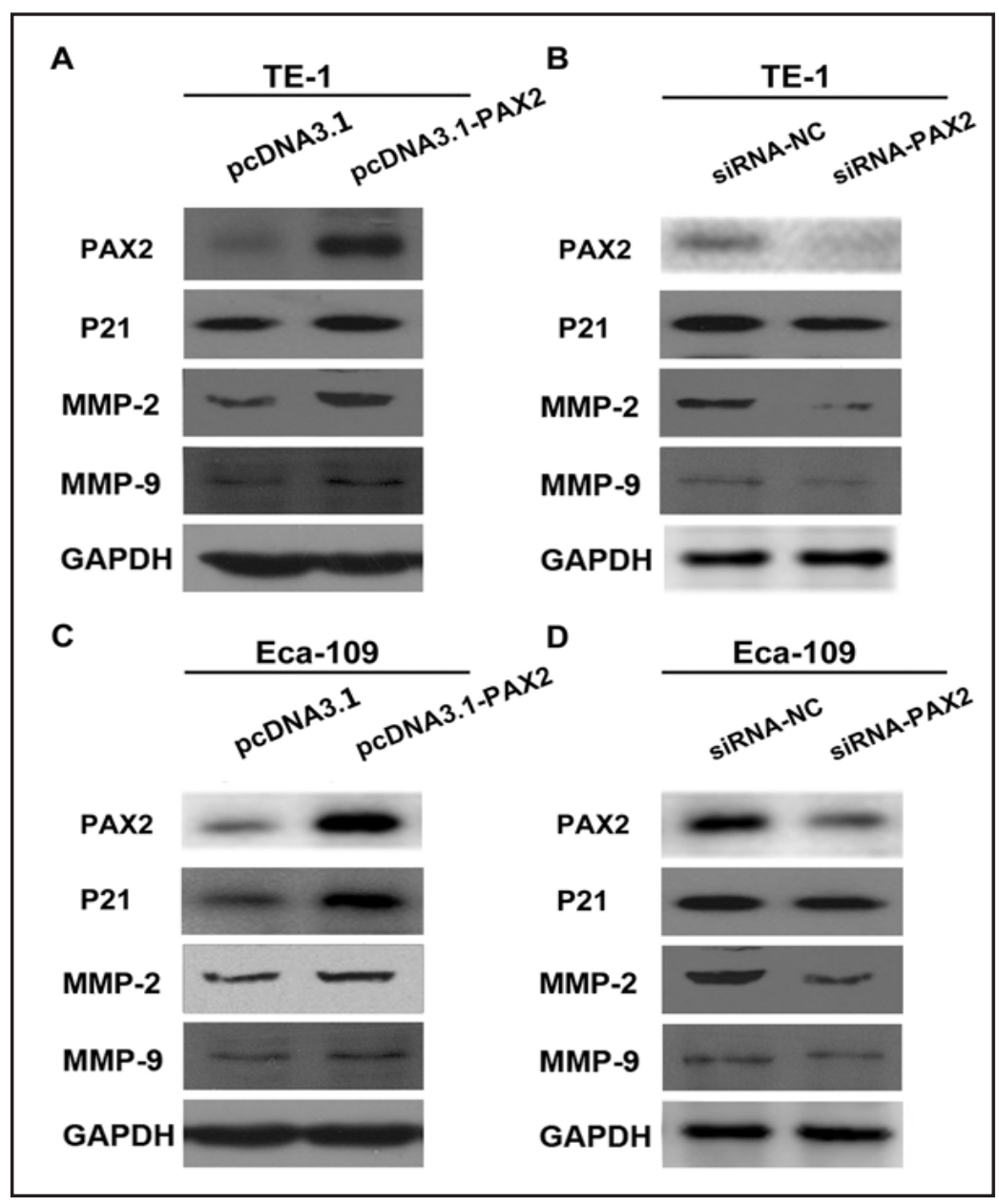

Fig. 5. Transwell assay of TE-1 cells after transfection with pcDNA3.1 or pcDNA3.1-PAX2 plus DMSO or $10 \mathrm{nM}$ batimasta treatment.

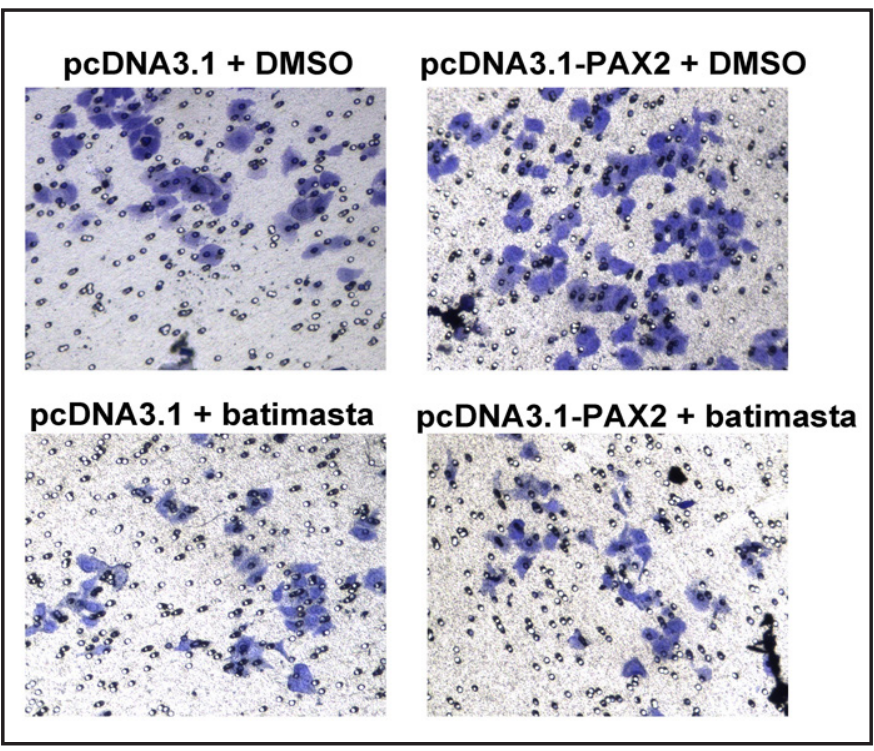

PAX2 stimulated IL-5 expression by binding to its promoter

Among PAX2 affected genes, we focused on interleukin-5 (IL-5), which has been reported to contribute to cancer metastasis [31,32]. Moreover, the bioinformatic tool TFSearch (available at www.cbrc.jp/research/db/TFSEARCH.html) predicted that the $I L-5$ promoter 


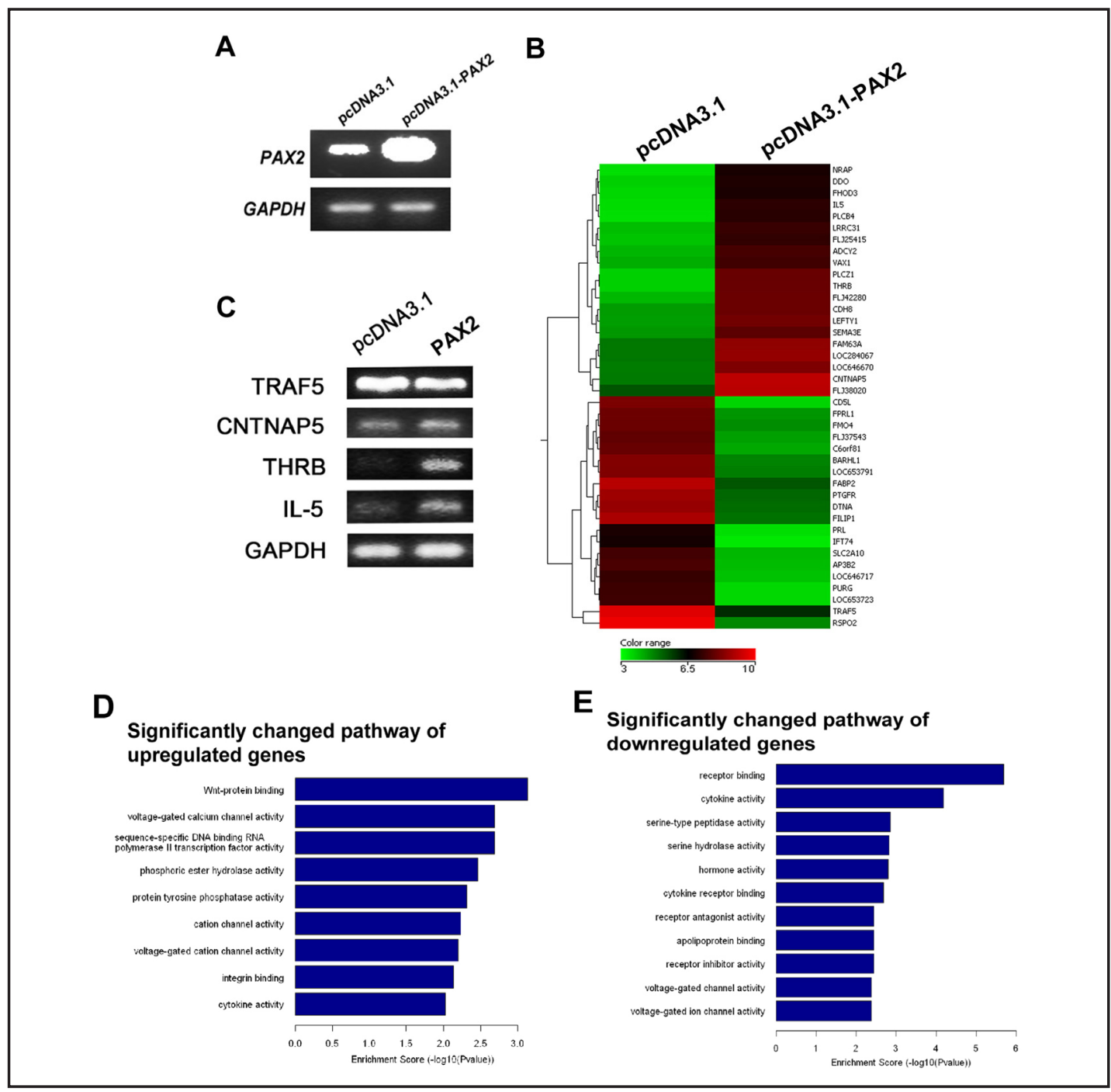

Fig. 6. Predicted significant pathways affected by PAX2 overexpression. (A) RT-PCR analysis of PAX2 mRNA in pcDNA3.1- and pcDNA3.1-PAX2-transfected TE-1 cells. (B) Heatmap of gene expression between pcDNA3.1- and pcDNA3.1-PAX2-transfected TE-1 cells. (C) RT-PCR analysis of mRNA levels in TE-1 cells after transfection with pcDNA3.1 or pcDNA3.1-PAX2. (D) Predicted significant pathways for upregulated genes. (E) Predicted significant pathways for downregulated genes.

harbors two PAX2 binding sites (Fig. 7A). It was of interest to explore the possibility that PAX2 mediated biological function through IL-5. The transactivating role of PAX2 on the $I L-5$ promoter was also measured using two luciferase constructs containing the $I L-5$ promoter with or without PAX2 binding sites (pGL3-1320 and pGL3-960, Fig. 7A). The results revealed that the expression of pGL3-1320 showed significantly increased luciferase activity compared with that of pGL3-960 in both TE-1 and Eca-109 cells (Fig. 7B). Moreover, transfection of PAX2 overexpression vector increased luciferase activity with $I L-5$ prommoter (Fig. 7C), indicating the positive role of PAX2 in $I L-5$ transcription.

Next, we determined the direct binding of PAX2 bound to the $I L-5$ promoter by ChIP. Indeed, in Eca-109 cells, the $I L-5$ promoter was specifically precipitated with a PAX2 antibody (Fig. 7D), indicating the presence of PAX2 bound to the $I L-5$ promoter in vivo. To confirm that PAX2 is an upstream regulator of IL-5 in esophageal cancer, we measured the effect of PAX2 on $I L-5$ transcription. As shown in Fig. 7E, $I L-5$ mRNA levels were induced in 
Liu et al.: Upregulation of PAX2 Promotes Metastasis in ESCC

Table 4. Micorarray analysis of gene expression changes between pcDNA3.1- and pcDNA3.1-PAX2-transfected TE-1 cells (pcDNA3.1-PAX2- Vs. pcDNA3.1-transfected cells)

\begin{tabular}{|c|c|c|c|}
\hline Gene Name & $\begin{array}{l}\text { Fold Change } \\
\text { Upregulated }\end{array}$ & Chromosome & Description \\
\hline THRB & 19.776 & $\operatorname{chr} 3$ & thyroid hormone receptor, beta \\
\hline CNTNAP5 & 19.507 & $\operatorname{chr} 2$ & contactin associated protein-like 5 \\
\hline PLCZ1 & 19.111 & $\operatorname{chr} 12$ & phospholipase $\mathrm{C}$, zeta 1 \\
\hline FLJ42280 & 15.890 & chr7 & FLJ42280 protein \\
\hline LEFTY1 & 13.561 & chr1 & left-right determination factor 1 \\
\hline FLJ38020 & 13.273 & chr1 & similar to absent in melanoma 1 \\
\hline LOC284067 & 12.973 & $\operatorname{chr} 17$ & hypothetical LOC284067 \\
\hline PLCB4 & 12.393 & $\operatorname{chr} 20$ & phospholipase $\mathrm{C}$, beta 4 \\
\hline IL-5 & 12.389 & $\operatorname{chr} 5$ & interleukin 5 (colony-stimulating factor) \\
\hline FAM63A & 12.237 & $\operatorname{chr} 1$ & family with sequence similarity 63 , member $\mathrm{A}$ \\
\hline $\mathrm{CDH8}$ & 12.202 & $\operatorname{chr} 16$ & cadherin 8 , type 2 \\
\hline ADCY2 & 10.991 & $\operatorname{chr} 5$ & adenylate cyclase 2 (brain) \\
\hline LOC646670 & 10.879 & $\operatorname{chr} 15$ & similar to COMM domain containing 4 \\
\hline N/A & 10.707 & $\operatorname{chr} 1$ & Homo sapiens KIAA1383 mRNA \\
\hline NRAP & 10.528 & $\operatorname{chr} 10$ & nebulin-related anchoring protein \\
\hline LRRC31 & 10.466 & $\operatorname{chr} 3$ & leucine rich repeat containing 31 \\
\hline SEMA3E & 10.295 & $\operatorname{chr} 7$ & sema domain, immunoglobulin domain (Ig), short basic domain \\
\hline FLJ25415 & 10.294 & chr2 & hypothetical protein FLJ25415 \\
\hline FHOD3 & 10.007 & $\operatorname{chr} 18$ & formin homology 2 domain containing 3 \\
\hline DDO & 9.860 & chr6 & D-aspartate oxidase \\
\hline Gene Name & $\begin{array}{l}\text { Fold Change } \\
\text { Downregulated }\end{array}$ & Chromosome & Description \\
\hline RSPO2 & 35.552 & chr8 & R-spondin 2 homolog (Xenopus laevis) \\
\hline CD5L & 24.067 & $\operatorname{chr} 1$ & CD5 molecule-like \\
\hline $\mathrm{N} / \mathrm{A}$ & 16.676 & $\operatorname{chr} 17$ & Homo sapiens cDNA FLJ41931 fis, clone PERIC2004429. \\
\hline FILIP1 & 15.068 & chr6 & filamin A interacting protein 1 \\
\hline LOC653723 & 14.231 & chr19 & similar to Sialic acid-binding Ig-like lectin 5 precursor (Siglec-5) \\
\hline PURG & 13.859 & chr8 & purine-rich element binding protein $\mathrm{G}$ \\
\hline C6orf81 & 13.065 & chr6 & chromosome 6 open reading frame 81 \\
\hline FABP2 & 13.008 & $\operatorname{chr} 4$ & fatty acid binding protein 2 , intestinal \\
\hline TRAF5 & 12.454 & chr1 & TNF receptor-associated factor 5 \\
\hline PTGFR & 12.288 & $\operatorname{chr} 1$ & prostaglandin $\mathrm{F}$ receptor (FP) \\
\hline AP3B2 & 12.243 & $\operatorname{chr} 15$ & adaptor-related protein complex 3 , beta 2 subunit \\
\hline BARHL1 & 12.043 & chr9 & BarH-like 1 (Drosophila) \\
\hline FPRL1 & 11.876 & chr19 & formyl peptide receptor-like 1 \\
\hline DTNA & 11.801 & $\operatorname{chr} 18$ & dystrobrevin, alpha \\
\hline FLJ37543 & 11.408 & $\operatorname{chr} 5$ & hypothetical protein FLJ37543 \\
\hline IFT74 & 11.379 & chr9 & intraflagellar transport 74 homolog (Chlamydomonas) \\
\hline LOC653791 & 11.284 & $\operatorname{chr} 5$ & similar to hypothetical protein MGC42105 \\
\hline PRL & 10.829 & chr6 & prolactin \\
\hline FMO4 & 10.825 & $\operatorname{chr} 1$ & flavin containing monooxygenase 4 \\
\hline LOC646717 & 10.796 & $\operatorname{chr} 22$ & hypothetical protein LOC646717 \\
\hline
\end{tabular}

PAX2-overexpressing TE-1 and Eca-109 cells. In addition, increased level of IL-5 promoted the metastasis of Eca-109 cells (Fig. 7F).

\section{Expression of IL-5 correlated with PAX2 in tissues}

The above mentioned results led us to investigate whether the expression level of PAX2 correlated with that of $I L-5$ in tissue samples. Quantitative real-time PCR was used to detect the expression levels of PAX2 and $I L-5$ mRNA in 24 normal esophageal and 60 ESCC tissue samples. PAX2 expression and $I L-5$ mRNA expression were found in 80/84 (95.2\%) and 78/84 (92.8\%) of esophageal derived samples, respectively. As shown in Fig. 7, the expression levels of PAX2 and $I L-5$ mRNA correlated significantly with each other (Pearson $\mathrm{r}$ $=0.456, P<0.0001$; Fig. 8).

\section{Discussion}

PAX2 has exhibited the multifunctional ability to regulate various biological processes, and PAX2 expression occurs in various types of benign and malignant tumors, including breast, ovarian, lung, colon, prostate, and lymphoma tumors [23, 24]. PAX2 exhibits higher expression in metastatic state than in non-metastatic prostate cancers [22]. In the present 


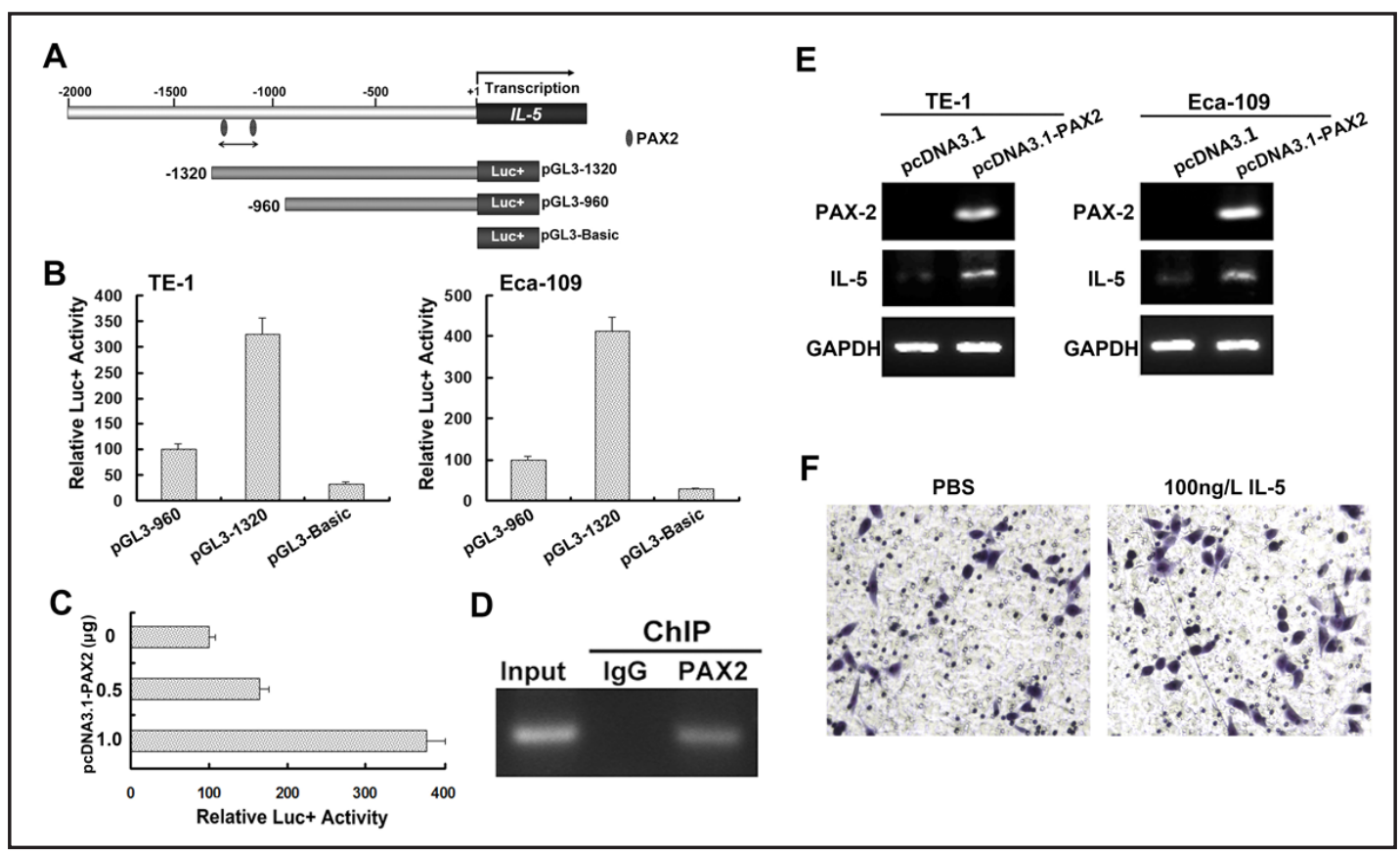

Fig. 7. PAX2 positively regulates IL-5 in esophageal cancer cells. (A) The diagram indicates the relative positions of transcription factor PAX2 in the $I L-5$ promoter. Truncated promoters were cloned upstream of the firefly luciferase reporter gene. (B) TE-1 cells were transfected with PAX2 overexpression vector (pcDNA3.1-PAX2) or control vector (pcDNA3.1). Luciferase reporters containing the $I L-5$ promoter were transfected into TE-1 and Eca-109 cells. After $24 \mathrm{~h}$ of incubation, luciferase activity was measured using the Dual-Luciferase Reporter Assay System (Promega). (C) Luciferase reporters containing the IL-5 promoter (pGL3-1320) were co-transfected with indicated doses of PAX2 overexpression vectors. Luciferase activity was measured $24 \mathrm{~h}$ post transfection. (D) ChIP assay of PAX2 binding to the $I L-5$ promoter in Eca-109 cells. The presence of PAX2 at the $I L-5$ promoter was verified by PCR. (E) RT-PCR analysis of PAX2, IL-5 and GAPDH mRNA levels in TE-1 and Eca-109 cells $48 \mathrm{~h}$ after transfection with pcDNA3.1 or pcDNA3.1-PAX2. (F) IL-5 promoted the metastasis in Eca-109 cells. Cells were mock treated (PBS) or treated with $100 \mathrm{ng} / \mathrm{L}$ IL-5 for $24 \mathrm{~h}$ and subjected to transwell assay.

Fig. 8. PAX2 positively regulates IL-5 in esophageal tissue samples. Quantitative real-time PCR was used to detect the expression levels of PAX2 and $I L-5$ mRNA in 24 normal esophageal and 60 ESCC tissue samples.

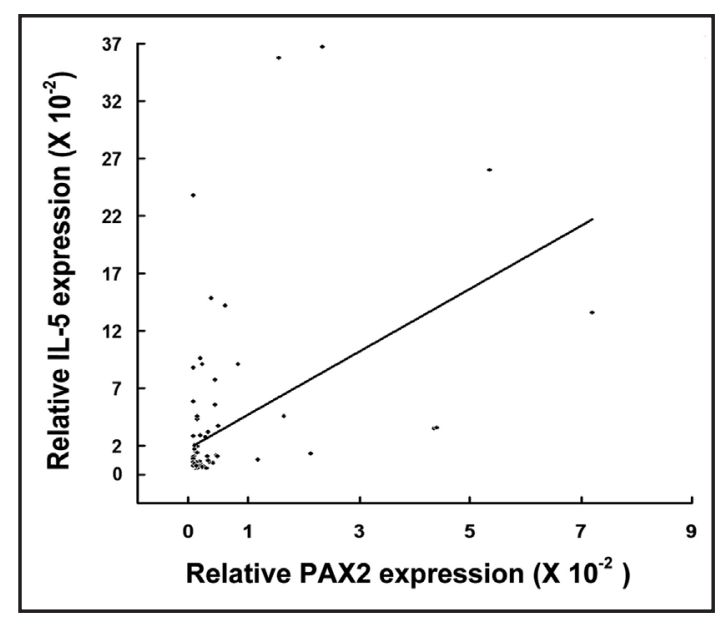

study, we found that the expression of PAX2 was significantly greater in tumor tissues than in normal tissues or tumor-adjacent tissues. The PAX2 promoter contains six hypoxia response elements (HREs), and PAX2 expression is induced by hypoxia but irrespective of methylation status [33]. Because of the hypoxia status of solid tumors, including esophageal cancer tumors [34], upregulation of PAX2 in cancers is likely to result from HIF1- $\alpha$ and/or 
HIF- $2 \alpha$. Because ESCC is one of the most aggressive cancers, to date, no effective measures are available to cure ESCC. The metastasis of lymphadenopathy is a major pathway for the spread of tumor cells, and lymphatic invasion is an important factor in the decision to pursue a therapeutic strategy and the evaluation of prognoses [35]. In this study, we found that PAX2 levels are correlated with tumor stage, pN and lymphatic invasion, indicating that PAX2 is involved in esophageal oncogenesis and tumor development and that PAX2 may be a predicator of malignant degree.

PAX2 overexpression exhibits oncogenic properties, such as anti-apoptosis, proliferation promotion and drug resistance in multiple cancers [36, 37]. The function of PAX2 in proliferation has proven to be controversial, depending on the genetic background of cells [18]. In this study, we found that PAX2 suppresses TE-1 and Eca-109 cells by upregulating P21. PAX2 has been reported to activate a variety of cell membrane proteins, and inhibition of PAX2-positive cells reduces cell motility and invasiveness in prostate, ovarian and bladder cancers $[18,22,38]$. Consistent with previous findings, we found that PAX2 overexpression resulted in markedly increased metastasis capacity in vitro and in vivo. Knockdown of PAX2 expression with a short hairpin RNA confirmed the role of PAX2 in the promotion of metastasis in ESCC cells, which supports the findings obtained by examining ESCC tissues that PAX2 expression is associated with $\mathrm{pN}$ and lymphatic invasion. The downstream target genes of PAX2 have gradually been identified, and GDNF has been reported to be a PAX2 target in medulloblastoma [36]. PAX2 can regulate metalloproteinase ADAM10 expression by driving melanoma metastasis [39]. In colon cancer cells, PAX2 upregulates Cyclin D1 mediated by AP-1 to promote cell proliferation [21]. To comprehensively understand the functional targets of PAX2 in esophageal cancer, we performed mRNA microarray-based screening analysis in TE-1 cells. Through this analysis, we found that PAX2 overexpression affected multiple genes that function in multiple pathways. The above-reported PAX2-regulated targets were not included in the PAX2 effected gene list, suggesting that PAX2 targets may be cancer-type-specific or conditional. Among PAX2-affected mRNAs, IL-5 has been shown to promote tumor metastasis in bladder cancer cells [31,32]. IL-5 is reported to be involved in a number of immune responses, such as helminth infection and allergy, by regulating the production and function of B cells, eosinophils, and basophils [40, 41]. However, little is known about the role of IL-5 in cancer cells. In this study, we demonstrated that esophageal TE-1 and Eca-109 cells express IL-5 mRNA and secrete IL-5, which promotes cell metastasis via an autocrine pathway. Moreover, two PAX2-binding sites were identified in the $I L-5$ promoter, and PAX2 stimulated IL-5 expression and secretion in esophageal cancer cells. The expression of PAX2 mRNA significantly correlated with that of $I L-5$ in normal esophageal and ESCC tissues. Taken together, we demonstrated IL-5 as a novel direct target of PAX2 in esophageal carcinoma.

\section{Conclusion}

In summary, we found that the PAX2 expression was significantly increased in tumor tissues and that its expression correlated with the ESCC stage, lymph node metastasis and lymphatic invasion in human ESCC tissue specimens. Furthermore, PAX2 overexpression increased metastasis capacity in vitro via the transcriptional upregulation of IL-5. Taken together, we demonstrated the overexpression of PAX2 in esophageal carcinoma and identified IL-5 as PAX2's effector for metastasis. Thus, PAX2 may be a biomarker for ESCC phenotypes and represents a novel therapeutic target.

\section{Disclosure Statement}

The authors have no conflict of interest. 


\section{Acknowledgements}

This work is supported by the National Natural Science Foundation of China (81472920 and 81372433), Natural Science Foundation of Jiangsu Province (BK2012561), Innovative Project of Jiangsu Province (BL2012046) and the Priority Academic Program Development of Jiangsu Higher Education Institutions (PAPD).

\section{References}

Siegel R, Naishadham D, Jemal A: Cancer statistics, 2013. CA Cancer J Clin 2013;63:11-30.

Rice TW, Blackstone EH: pT2N0M0 esophageal squamous cell cancer: location, grade, and statistics. J Thorac Cardiovasc Surg 2013;145:1426-1427.

Enzinger PC, Mayer RJ: Esophageal cancer. N Engl J Med 2003;349:2241-2252.

D'Amico TA: Outcomes after surgery for esophageal cancer. Gastrointest Cancer Res 2007;1:188-196.

Nebert DW: Transcription factors and cancer: an overview. Toxicology 2002;181:131-141.

Libermann TA, Zerbini LF:Targeting transcription factors for cancer gene therapy. Curr Gene Ther 2006;6;17-33.

7 Wang Q, Fang WH, Krupinski J, Kumar S, Slevin M, Kumar P: Pax genes in embryogenesis and oncogenesis. J Cell Mol Med 2008;12:2281-2294. Maulbecker CC, Gruss P: The oncogenic potential of Pax genes. Embo J 1993;12:2361-2367.

-9 Bouchard M, Grote D, Craven SE, Sun Q, Steinlein P, Busslinger M: Identification of Pax2-regulated genes by expression profiling of the mid-hindbrain organizer region. Development 2005;132:2633-2643.

-10 Torres M, Gomez-Pardo E, Dressler GR, Gruss P: Pax-2 controls multiple steps of urogenital development. Development 1995;121:4057-4065.

-11 Torban E, Eccles MR, Favor J, Goodyer PR: PAX2 suppresses apoptosis in renal collecting duct cells. Am J Pathol 2000;157:833-842.

- 12 Sanyanusin P, Schimmenti LA, McNoe LA, Ward TA, Pierpont ME, Sullivan MJ, Dobyns WB, Eccles MR: Mutation of the PAX2 gene in a family with optic nerve colobomas, renal anomalies and vesicoureteral reflux. Nat Genet 1995;9:358-364.

-13 Martinovic-Bouriel J, Benachi A, Bonniere M, Brahimi N, Esculpavit C, Morichon N, Vekemans M, Antignac C, Salomon R, Encha-Razavi F, Attié-Bitach T, Gubler MC: PAX2 mutations in fetal renal hypodysplasia. Am J Med Genet A 2010;152:830-835.

-14 Igarashi T, Ueda T, Suzuki H, Tobe T, Komiya A, Ichikawa T, Ito H: Aberrant expression of Pax-2 mRNA in renal cell carcinoma tissue and parenchyma of the affected kidney. Int J Urol 2001;8:60-64.

15 Gnarra JR, Dressler GR: Expression of Pax-2 in human renal cell carcinoma and growth inhibition by antisense oligonucleotides. Cancer Res 1995;55:4092-4098.

16 Fonsato V, Buttiglieri S, Deregibus MC, Puntorieri V, Bussolati B, Camussi G: Expression of Pax2 in human renal tumor-derived endothelial cells sustains apoptosis resistance and angiogenesis. Am J Pathol 2006;168:706-713.

-17 Tung CS, Mok SC, Tsang YT, Zu Z, Song H, Liu J, Deavers MT, Malpica A, Wolf JK, Lu KH, Gershenson DM, Wong KK: PAX2 expression in low malignant potential ovarian tumors and low-grade ovarian serous carcinomas. Mod Pathol 2009;22:1243-1250.

18 Song H, Kwan SY, Izaguirre DI, Zu Z, Tsang YT, Tung CS, King ER, Mok SC, Gershenson DM, Wong KK: PAX2 Expression in Ovarian Cancer. Int J Mol Sci 2013;14: 6090-6105.

-19 Kahraman K, Kiremitci S, Taskin S, Kankaya D, Sertcelik A, Ortac F: Expression pattern of PAX2 in hyperplastic and malignant endometrium. Arch Gynecol Obstet 2012;286:173-178.

20 Beauchemin D, Lacombe C, Van Themsche C: PAX2 is activated by estradiol in breast cancer cells of the luminal subgroup selectively, to confer a low invasive phenotype. Mol Cancer 2011;10:148.

21 Zhang HS, Yan B, Li XB, Fan L, Zhang YF, Wu GH, Li M, Fang J: PAX2 protein induces expression of cyclin D1 through activating AP-1 protein and promotes proliferation of colon cancer cells. J Biol Chem 2012;287:44164-44172.

22 Ueda T, Ito S, Shiraishi T, Kulkarni P, Ueno A, Nakagawa H, Kimura Y, Hongo F, Kamoi K, Kawauchi A, Miki T: Hyper-expression of PAX2 in human metastatic prostate tumors and its role as a cancer promoter in an in vitro invasion model. Prostate 2014;73:1403-1412. 
Liu et al.: Upregulation of PAX2 Promotes Metastasis in ESCC

23 Muratovska A, Zhou C, He S, Goodyer P, Eccles MR: Paired-Box genes are frequently expressed in cancer and often required for cancer cell survival. Oncogene 2003;22:7989-7997.

24 Li CG, Eccles MR: PAX Genes in Cancer; Friends or Foes? Front Genet 2012;3:6.

-25 Liu P, Zhou J, Zhu H, Xie L, Wang F, Liu B, Shen W, Ye W, Xiang B, Zhu X, Shi R, Zhang S: VEGF-C promotes the development of esophageal cancer via regulating CNTN-1 expression. Cytokine 2011;55:8-17.

26 Luo J, Zhou X, Ge X, Liu P, Cao J, Lu X, Ling Y, Zhang S: Upregulation of Ying Yang 1 (YY1) suppresses esophageal squamous cell carcinoma development through heme oxygenase-1. Cancer science 2013;104:1544-1551.

27 Yamasaki M, Miyata H, Miyazaki Y, Takahashi T, Kurokawa Y, Nakajima K, Takiguchi S, Mori M, Doki Y: Evaluation of the nodal status in the 7th edition of the UICC-TNM classification for esophageal squamous cell carcinoma: proposed modifications for improved survival stratification: impact of lymph node metastases on overall survival after esophagectomy. Ann Surg Oncol 2014;21:2850-2856

28 Zhang S, Lu J, Zhao X, Wu W, Wang H, Wu Q, Chen X, Fan W, Chen H, Wang F, Hu Z, Jin L, Wei Q, Shen H, Huang W, Lu D: A variant in the CHEK2 promoter at a methylation site relieves transcriptional repression and confers reduced risk of lung cancer. Carcinogenesis 2010;31:1251-1258.

-29 Abbas T, utta A: p21 in cancer: intricate networks and multiple activities. Nat Rev Cancer 2009; 9:400-414.

- 30 Martinez LA, Yang J, Vazquez ES, Rodriguez-Vargas Mdel C, Olive M, Hsieh JT, Logothetis CJ, Navone NM: p21 modulates threshold of apoptosis induced by DNA-damage and growth factor withdrawal in prostate cancer cells. Carcinogenesis 2002;23:1289-1296.

-31 Lee EJ, Lee SJ, Kim S, Cho SC, Choi YH, Kim WJ, Moon SK: Interleukin-5 enhances the migration and invasion of bladder cancer cells via ERK1/2-mediated MMP-9/NF-kappaB/AP-1 pathway: involvement of the p21WAF1 expression. Cell Signal 2013;25:2025-2038.

-32 Lee EJ, Park SS, Kim WJ, Moon SK: IL-5-induced migration via ERK1/2-mediated MMP-9 expression by inducing activation of NF-kappaB in HT1376 cells. Oncol Rep 2012;28:1084-1090.

-33 Luu VD, Boysen G, Struckmann K, Casagrande S, von Teichman A, Wild PJ, Sulser T, Schraml P, Moch H: Loss of VHL and hypoxia provokes PAX2 up-regulation in clear cell renal cell carcinoma. Clin Cancer Res 2009;15:3297-3304.

-34 Powis G, Kirkpatrick L: Hypoxia inducible factor-1alpha as a cancer drug target. Mol Cancer Ther 2004;3:647-654.

35 Wilso, M, Rosato EL, Chojnacki KA, Chervoneva I, Kairys JC, Cohn HE, Rosato FS, Berger AC: Prognostic significance of lymph node metastases and ratio in esophageal cancer. J Surg Res 2008;146:11-15.

- 36 Burger MC, Brucker DP, Baumgarten P, Ronellenfitsch MW, Wanka C, Hasselblatt M, Eccles MR, Klingebiel T, Weller M, Rieger J, Mittelbronn M, Steinbach JP: PAX2 is an antiapoptotic molecule with deregulated expression in medulloblastoma. Int J Oncol 2012;41:235-241.

- 37 Hurtado A, Holmes KA, Geistlinger TR, Hutcheson IR, Nicholson RI, Brown M, Jiang J, Howat WJ, Ali S, Carroll JS: Regulation of ERBB2 by oestrogen receptor-PAX2 determines response to tamoxifen. Nature 2008:456:663-666.

- 38 Khoubehi B, Kessling AM, Adshead JM, Smith GL, Smith RD, Ogden CW: Expression of the developmental and oncogenic PAX2 gene in human prostate cancer. J Urol 2001;165:2115-2120.

- 39 Lee SB, Doberstein K, Baumgarten P, Wieland A, Ungerer C, Burger C, Hardt K, Boehncke WH, Pfeilschifter J, Mihic-Probst D, Mittelbronn M, Gutwein P: PAX2 regulates ADAM10 expression and mediates anchorageindependent cell growth of melanoma cells. PloS one 2011;6:e22312.

40 Adachi T, Alam R: The mechanism of IL-5 signal transduction. Am J Physiol 1998;275:C623-633.

41 Kurowska-Stolarska M, Kewin P, Murphy G, Russo RC, Stolarski B, Garcia CC, Komai-Koma M, Pitman N, Li Y, Niedbala W, McKenzie AN, Teixeira MM, Liew FY, Xu D: IL-33 induces antigen-specific IL-5+ T cells and promotes allergic-induced airway inflammation independent of IL-4. J Immunol 2008;181:4780-4790. 